\title{
Rapid Detection of Ustilaginoidea virens from Rice using Loop-Mediated Isothermal Amplification Assay
}

\author{
Xue Yang, Mohamed N. Al-Attala, Yong Zhang, Ai-Fang Zhang, Hao-Yu Zang, Chun-Yan Gu, Tong-Chun Gao, and Yu Chen, ${ }^{\dagger}$ In- \\ stitute of Plant Protection and Agro-products Safety, Anhui Academy of Agricultural Sciences, Hefei 230031, China; Scientific Observing and \\ Experimental Station of Crop Pests in Hefei, Ministry of Agriculture, China; and Laboratory of Quality \& Safety Risk Assessment for Agro- \\ Products, Hefei, Ministry of Agriculture, China; and Key Laboratory of Anhui Agricultural Sciences; Mohamed N. Al-Attala, Plant Pathology \\ Unit, Plant Protection Department, Desert Research Center, Cairo 11753, Egypt; Farman Ali, Institute of Plant Protection and Agro-products \\ Safety, Anhui Academy of Agricultural Sciences; and Department of Agriculture, Abdul Wali Khan University Mardan, Pakistan; Yun-Fei \\ Li and Jian Yao, Anhui Entry-Exit Inspection and Quarantine Bureau, Hefei 230022, China; and Jin-Guo Zhu, Hunan Entry-Exit Inspection \\ and Quarantine Bureau, Changsha 410004, China
}

\begin{abstract}
Ustilaginoidea virens is an important fungus that causes rice false smut disease. This disease significantly reduces both grain yield and quality. Various methods have been developed for the detection of $U$. virens but most of these methods need sophisticated equipment such as a thermal cycler. Here, we present a loop-mediated isothermal amplification (LAMP) assay for the specific detection of $U$. virens. This assay used a specific region of the $U v G-\beta 1$ gene (212-bp region) to design six LAMP primers. The LAMP assay was optimized by the combination of rapidity, simplicity, and high sensitivity for the detection of about $1 \mathrm{pg}$ of target genomic DNA in the reaction whereas, with polymerase chain reaction

(PCR), there was no amplification of DNA with concentrations less than $1 \mathrm{ng}$. Among the genomic DNA of 22 fungus species and two strains of $U$. virens, only the tube containing the DNA of $U$. virens changed to yellowish green with SYBR Green I. The color change was indicative of DNA amplification. No DNA was amplified from either the other 22 fungus species or the negative control. Moreover, 20 spikelets and 22 rice seed samples were used for the detection of rice false smut via LAMP. The results were comparable with conventional PCR. We conclude that gene $U v G-\beta 1$ coupled with LAMP assay, can be used for the detection and identification of $U$. virens gene via LAMP.
\end{abstract}

Rice is one of the most-consumed foods in the world and a principal source of nutrition for the world's population, especially in Asia (Laborte et al. 2012; Young 1999). Rice production occupies the third-highest position in worldwide production in the agricultural commodity list, after sugarcane and maize (FAO 2015). In China, the total production of rice is more than 20 million tons.

Rice is infected by several different pathogens such as Cochliobolus miyabeanus, Sclerophthora macrospora, Tilletia barclayana, and Ustilaginoidea virens (Ono and Uehara 1949). All of these pathogens cause diseases that diminish both quality and yield of rice. One of the serious diseases is rice false smut, also known as pseudosmut or green smut, caused by $U$. virens (Ono and Uehara 1949).

${ }^{\dagger}$ Corresponding author: Y. Chen; E-mail: chenyu66891@ sina.com

X. Yang, M. N. Al-Attala, and Y. Zhang contributed equally to this work and share joint first authorship for this article.

Funding: This research was supported by (i) the National Key Research and Development Program of China (2016YFD0200806); (ii) Project of Agro-Product Safety Monitoring from the Ministry of Agriculture, China; (iii) the National Key Research and Development Program of China (2016YFD0300700); (iv) National Natural Science Foundation of China (31672061); (v) Special Fund for Quality Inspection Research in the Public Interest from the General Administration of Quality supervision, Inspection, and Quarantine of the People's Republic of China (201410076); (vi) the Research Program from the General Administration of Quality supervision, Inspection, and Quarantine of the People's Republic of China (2012IK267, 2010IK249, 2014IK011, and 2017IK056); (vii) Science and Technological Fund of Anhui Province for Outstanding Youth (1408085J02); (viii) the Anhui Provincial "115" Innovation Team; (ix) the Natural Science Foundation of Anhui Province (1808085QC91); and (x) the program for construction of the Key Laboratory of Anhui Academy of Agricultural Sciences (18S1103). We thank the Ministry of Science and Technology China for the financial support to M. N. Al-Attala under the Talented Young Scientist Program.

Accepted for publication 8 March 2018.

C 2018 The American Phytopathological Society
$U$. virens is an ascomycete, which can produce both anamorph (chlamydospores) and sexual (ascospores) spores in its life cycle, with multiple propagates. The teleomorph stage of false smut fungus is named Villosiclava virens. Both sexual and anamorph spores can infect the rice spikelet and convert a rice grain into a ball of mycelia (Fan et al. 2016; Song et al. 2016). The symptoms of rice false smut disease appear on the panicle of spikelets (Ashizawa et al. 2012; Hu et al. 2014). The fungus produces ustiloxin, mycotoxin, and phytotoxin. Ustiloxin is a kind of cyclopeptide mycotoxins and is toxic to humans and animals (Koiso et al.1994, Li et al. 1995; Ludueña et al. 1994). Many studies have reported the infection mechanism of $U$. virens in rice during different stages (Fan et al. 2016; Tanaka et al. 2017; Tang et al. 2013). Several plant families could be colonized by $U$. virens without showing any visible symptoms under high humidity and free water conditions (Fan et al. 2014). Moreover, they reported that $U$. virens has epiphytic characteristics. In Egypt, 1.0 to $10.9 \%$ loss occurs in rice production due to rice false smut disease (Atia 2004). With population growth and reduction in farmland, intensive farming systems are used to meet the growing demand for food (Tilman et al. 2002). However, by using intensive farming systems, an increase in spread and severity of plant diseases is being noticed. This points out the need to develop easy assays for the detection and identification of plant pathogens.

Advanced molecular techniques such as polymerase chain reaction (PCR), nested-PCR, and real-time PCR can give reliable and specific results for solving this problem. Although these techniques efficiently give accurate results, it is hard to use them in every laboratory with limited resources, especially in developing countries, where they do not have access to more sophisticated equipment such as thermal cyclers. However, loop-mediated isothermal amplification (LAMP) just needs a constant temperature. In addition, problems arise with the efficiency of Taq DNA polymerase that affect the amplification of the target DNA such as the boold, feces, and meat (Al-Soud and Rådström 2000; Monteiro et al. 1997).

Hence, Notomi et al. (2000) developed a new technique for the amplification of DNA called LAMP. For rapid identification of different diseases in human, animals, and plants, LAMP is preferred for convenient and easier amplification of target DNA. Therefore, in comparison 
with other molecular methods, LAMP could be a potential alternative for detecting $U$. virens, especially in field settings. Previous studies have reported the use of LAMP assays for the detection and identification of many different plant pathogens such as Phytophthora sojae, Fusarium graminearum, Sclerotinia sclerotiorum, Meloidogyne enterolobii, Botrytis cinerea, and P. ramorum (Dai et al. 2012; Duan et al. 2014a; Niessen and Vogel 2010; Niu et al. 2012; Tomlinson et al.

Table 1. List of fungal species used for testing the specificity in the loopmediated isothermal amplification (LAMP) and polymerase chain reaction (PCR) assays

\begin{tabular}{|c|c|c|c|c|}
\hline Species & Host & Source $^{\mathbf{a}}$ & LAMP & PCR \\
\hline Ustilaginoidea virens (strain 1 ) & Rice & AAAS & + & + \\
\hline$U$. virens (strain2) & Rice & AAAS & + & + \\
\hline Alternaria alternata & Pear & AAAS & - & - \\
\hline Ascochyta eriobotryae & Loquat & AAAS & - & - \\
\hline Bipolaris sorokiniana & Wheat & AAAS & - & - \\
\hline Botryosphaeria dothidea & Pear & AAAS & - & - \\
\hline Coniella granati & Pomegranate & AAAS & - & - \\
\hline Coniothyrium diplodiella & Grape & AAAS & - & - \\
\hline Diplodia sp. & Dragon fruit & AAAS & - & - \\
\hline Fusarium fujikuroi & Rice & AAAS & - & - \\
\hline F. oxysporum f. sp. melonis & Strawberry & AAAS & - & - \\
\hline Gaeumannomyces graminis & Wheat & AAAS & - & - \\
\hline Glomerella acutata & Nectarine & AAAS & - & - \\
\hline Monilinia fructicola & Peach & AAAS & - & - \\
\hline Nigrospora sphaerica & Kiwi fruit & AAAS & - & - \\
\hline Pestalotiopsis theae & Loquat & AAAS & - & - \\
\hline Punicae granati & Pomegranate & AAAS & - & - \\
\hline Pyricularia grisea & Rice & AAAS & - & - \\
\hline Sclerotinia sclerotiorum & Pear & AAAS & - & - \\
\hline Metarhizium anisopliae & Insect & AAAS & - & - \\
\hline Claviceps purpurea & Wheat & AAAS & - & - \\
\hline Rhizoctonia solani & Rice & AAAS & - & - \\
\hline Tilletia horrida & Rice & AAAS & - & - \\
\hline F. graminearum & Wheat & AAAS & - & - \\
\hline
\end{tabular}

${ }^{\text {a }}$ AAAS = Anhui Academy of Agricultural Sciences.
2007, 2010). LAMP assays have also been used for detecting resistance mutation in the populations of $F$. graminearum (Duan et al. 2014b).

For precise detection and identification of different organisms, the specific gene or part of a gene such as the A3aPro element, FggaoA gene, Ssos 5 gene, intergenic spacer (ITS), 5S ribosomal DNA (5S rDNA), or ITS2 segment is chosen for the detection and identification of $P$. sojae, F. graminearum, S. sclerotiorum, M. enterolobii, $B$. cinerea, and $P$. ramorum, respectively (Dai et al. 2012; Duan et al. 2014a; Niessen and Vogel 2010; Niu et al. 2012; Tomlinson et al. 2007, 2010). Some of the previous works reported the detection of $U$. virens through PCR and real-time PCR based on the rDNA internal transcribed spacers and the 5.8S rDNA gene (Ashizawa et al. 2010; Zhou et al. 2003). The first isolation and characterization of gene $U v G-\beta 1$ was reported by Liu et al. (2010), and is identified under the trimeric $\mathrm{G}$ proteins (GTP binding proteins). GTP binding proteins play a pivotal role in signal transduction pathways. $G$ proteins are heterotrimers consisting of $\alpha, \beta$, and $\gamma$ subunits. They are involved in growth, sporulation, mating and virulence in filamentous fungi (Charoensopharat et al. 2008; Hsueh et al. 2007; Nishimura et al. 2003; Tzima et al. 2012; Wang et al. 2000; Yu et al. 2008). $U v G-\beta 1$ is also thought to be involved in the pathogenicity of $U$. virens (Liu et al. 2010).

This is the first report on a LAMP assay for the detection and identification of rice false smut fungal disease, which provides more sensitive and reliable detection than traditional assessment methods. Moreover, a LAMP assay will help us by providing easier identification of $U$. virens, and is more cost effective for detecting the disease in the field.

\section{Materials and Methods}

Fungal isolates. The fungal isolates used in this study were from rice fungal pathogens, phylogenetically related fungal pathogens (Zhang et al. 2014), or other common fungal pathogens (Table 1). The infected rice samples showing typical false smut symptoms were collected from fields in Anhui Province of China. Other fungal isolates were obtained from the culture held at the Anhui Academy of Agricultural Sciences. For pure culture isolation of $U$. virens, the method described by Chen et al. (2014) was used. Briefly, the false smut balls were surface sterilized in $0.1 \% \mathrm{NaClO}$ for $5 \mathrm{~min}$, followed by washing in distilled water for $30 \mathrm{~s}$ After rinsing, half of the false

$\mathbf{A}_{1}$

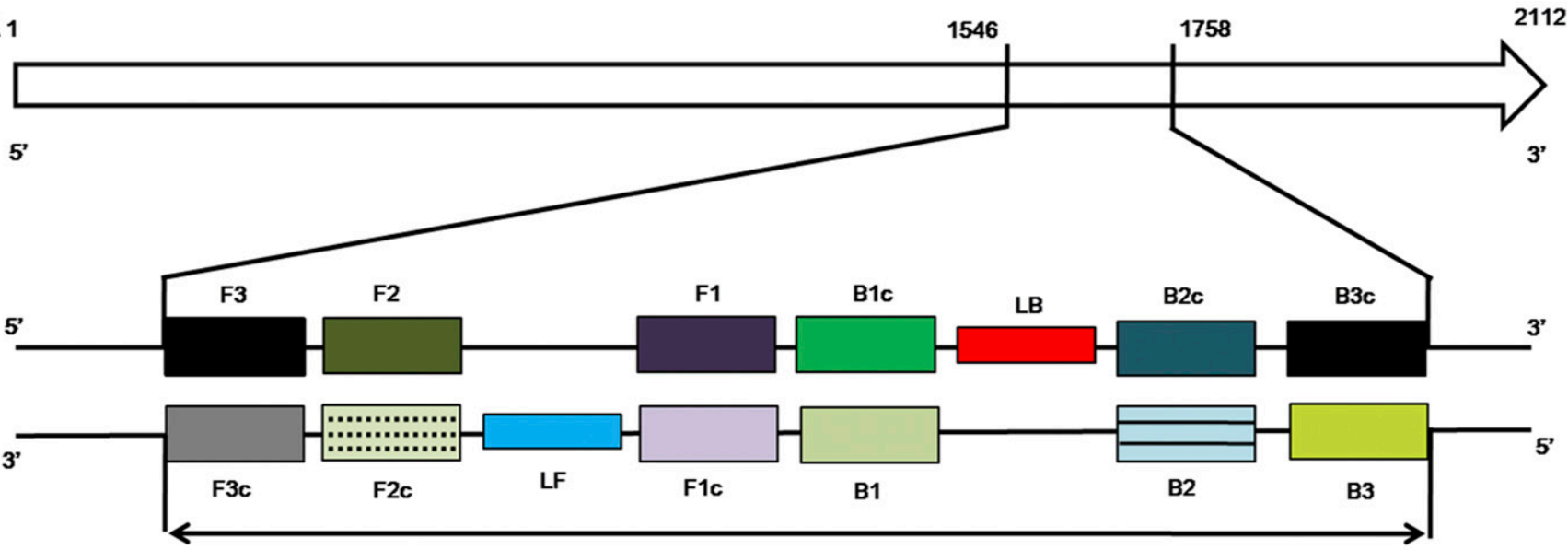

212bp

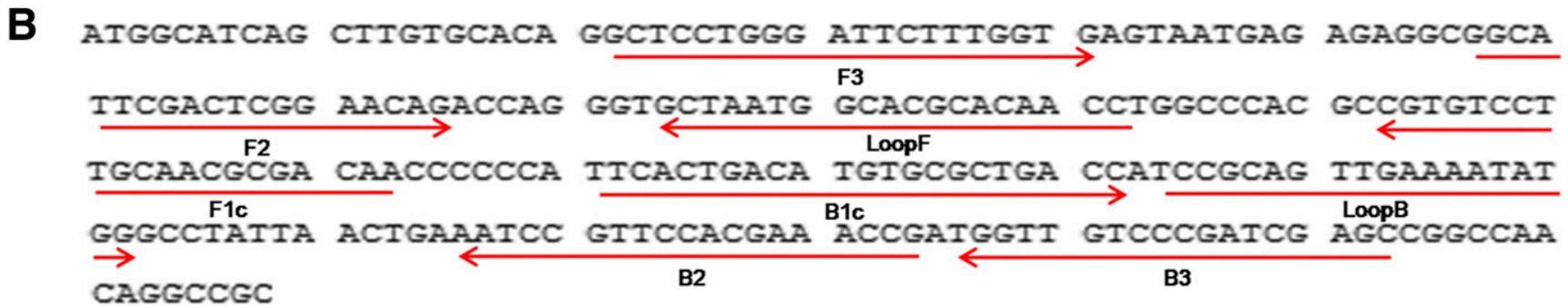

Fig. 1. Design of loop-mediated isothermal amplification (LAMP) primers for the detection of specific regions in gene UvG- $\beta 1$ (GU014921.1) in Ustilaginoidea virens genome. A, Schematic illustration of the LAMP primers used in this study. F1C and B1C are complementary to F1 and B1, respectively. B, Arrows show sequences of the LAMP primers. 
smut balls were transferred to petri dishes containing potato dextrose agar (PDA) and incubated at $28^{\circ} \mathrm{C}$ for 1 week. For pure culture, a single germinated chlamydospore was transferred to new PDA plates and stored at $4{ }^{\circ} \mathrm{C}$ for 3 to 4 weeks. Other pathogens were used for studying the specificity of LAMP primers (Table 1). These pathogens were cultured on PDA at $25^{\circ} \mathrm{C}$ for 2 weeks before use and stored at $4^{\circ} \mathrm{C}$. All of the isolates were identified according to their morphological features.

Extraction of DNA. Genomic DNA of $U$. virens and other pathogens was extracted using the Fungal DNA Mini Kit (Omega Biotek) according to the manufacturer's protocol. The DNA concentration for each sample was determined by Nanodrop (NanoVue Plus; GE Healthcare Life Sciences).

Primer designing. The National Center for Biotechnology Information (NCBI) (https://www.ncbi.nlm.nih.gov) database was searched via BLAST for various $U$. virens genes. The selected genes were blasted again to select the most specific sequence for the identification of this particular pathogen. A specific region on gene $U v G$ $\beta 1$ was selected after the second BLAST result (https://blast.ncbi. nlm.nih.gov/Blast.cgi). The specific site, showing no similarity to genes from any other pathogen until October 2016, was located from 1,546 to 1,758 bp on gene $U v G-\beta 1$ (Fig. $1 \mathrm{~A}$ and B). The LAMP primers were designed based on a specific region in $U$. virens; that is, the GTP binding protein $\beta$ subunit ( $U v G-\beta 1)$ gene (GU014921), using the Primer explorer V4 software program (http://primerexplorer. jp/e/) (Eiken Chemical Co., Ltd.). To start the LAMP reaction, the software gave out a LAMP primer set comprising a forward inner primer (FIP; consisting of F1c and F2), backward inner primer (BIP; consisting of B1c and B2), and F3 and B3 primers. Moreover, loop forward (LF) and loop backward (LB) primers were designed for increasing the efficiency of the LAMP reaction. The position and sequence of the LAMP primers used in this study is shown in Figure 1. These primers were synthesized by Invitrogen Trading Shanghai Co., Ltd. (Table 2).

LAMP reaction. For the optimization of reagents, the LAMP reaction was prepared by mixing $2.5 \mu \mathrm{l}$ of $10 \times$ isothermal amplification buffer (New England BioLabs), $112.5 \mu \mathrm{M} \mathrm{MgCl} 2$ (Sangon), $35 \mu \mathrm{M}$ dNTP Mix (Sangon), $40 \mu \mathrm{M}$ each FIP and BIP primer, $5 \mu \mathrm{M}$ each F3 and B3 primer, $1 \mu \mathrm{M}$ each LF and LB primer, $2 \mu \mathrm{l}$ of DNA, 0.8 to $1.6 \mathrm{M}$ betaine (Sigma-Aldrich), 100 to $200 \mathrm{mM}$ hydroxynaphthol blue (HNB), and $8 \mathrm{U}$ of Bst 2.0 WarmStart DNA polymerase (New England BioLabs). In addition, double-distilled (dd) $\mathrm{H}_{2} \mathrm{O}$ was added to make up the final volume to $25 \mu$ l. When replacing HNB with SYBR Green I, it was not added to the reaction mixture but $0.25 \mu \mathrm{l}$ was added to each tube after amplification. Reaction tubes were placed in a thermal cycler (Bio-Rad) and incubated at $65^{\circ} \mathrm{C}$ for $1 \mathrm{~h}$. The amplification was ended by heating at $80^{\circ} \mathrm{C}$ for $10 \mathrm{~min}$.

LAMP reactions were examined based on the change in color of HNB, SYBR Green I, and gel electrophoresis (2\% agarose gel for $50 \mathrm{~min}$ at $80 \mathrm{~V}$ ). Each treatment was replicated three times, and the experiment was repeated twice. The LAMP tubes were photographed with a Panasonic digital camera (model DMC-FZ28GK).

Assay of sensitivity and specificity in LAMP and PCR methods. To compare the sensitivity of PCR and LAMP, different concentrations of genomic DNA of $U$. virens $\left(10\right.$ to $\left.10^{-8} \mu \mathrm{g} / \mu \mathrm{l}\right)$ were used. For PCR, F3 and B3 primers were used to amplify the same specific region of gene $U v G-\beta 1$. PCR conditions included initial denaturation at $95^{\circ} \mathrm{C}$ for $3 \mathrm{~min}$; followed by 35 cycles of $95^{\circ} \mathrm{C}$ for $30 \mathrm{~s}, 60^{\circ} \mathrm{C}$ for 30 s, and $72^{\circ} \mathrm{C}$ for $30 \mathrm{~s}$; and a final extension at $72^{\circ} \mathrm{C}$ for $10 \mathrm{~min}$. The total volume of PCR was $25 \mu \mathrm{l}$, which contained $9.5 \mu \mathrm{l}$ of $\mathrm{ddH}_{2} \mathrm{O}, 1 \mu \mathrm{l}$ of genomic DNA of $U$. virens, $10 \mu \mathrm{M}$ each primer (F3 and B3), and $12.5 \mu \mathrm{l}$ of $2 \times$ Taq Master (novoprotein). After the amplification, the
PCR products were examined by running them on $1.0 \%$ agarose gel for $30 \mathrm{~min}$ at $120 \mathrm{~V}$. DNA ladder DL2000 was used for size references. To study the specificity of LAMP and PCR, 22 different fungi were used in the study in addition to two strains of $U$. virens (Table 1). The assays were evaluated based on change in the color of HNB and SYBR Green I in amplification tubes for LAMP and on $1.0 \%$ agarose gel electrophoresis for PCR. There were three replicates for each treatment and the experiment was repeated twice.

Detection of rice false smut pathogen in the field samples and rice seed. The 20 grains per sampled spikelet (healthy or infected) at rice booting stage were randomly collected and used for the detection. The DNA of the grains was isolated by using the Plant DNA Mini Kit (Omega Biotek) according to the manufacturer's protocol. The DNA concentration for each sample was determined by Nanodrop (NanoVue Plus; GE Healthcare Life Sciences). The extracted DNA was used for LAMP detection as described above and conventional PCR detection as described by a previous study (Chen et al. 2014).

For direct analysis of rice seed, 22 samples of healthy and infected seed were collected from the field in Anhui Province and stored for 30 days at room temperature. Then, $10 \mathrm{~g}$ of seed from each sample was put in a $50-\mathrm{ml}$ tube and sterile pure water was added up to $50 \mathrm{ml}$. The rice samples were drenched for $5 \mathrm{~min}$. Next, the saturated seed were centrifuged at 12,000 rpm for $10 \mathrm{~min}$. After centrifuging, $10 \mu \mathrm{l}$ was taken from each sample and used as the DNA templates for LAMP and PCR assays (Chen et al. 2014). For the LAMP assay, the amplification tubes were analyzed using SYBR Green I, and the PCR products were analyzed on $1.0 \%$ agarose gel electrophoresis. The experiment was repeated twice.

\section{Results}

Designing of LAMP primers and assay. Six LAMP primers for gene $U v G-\beta 1$ were obtained using the Primer explorer V4 software

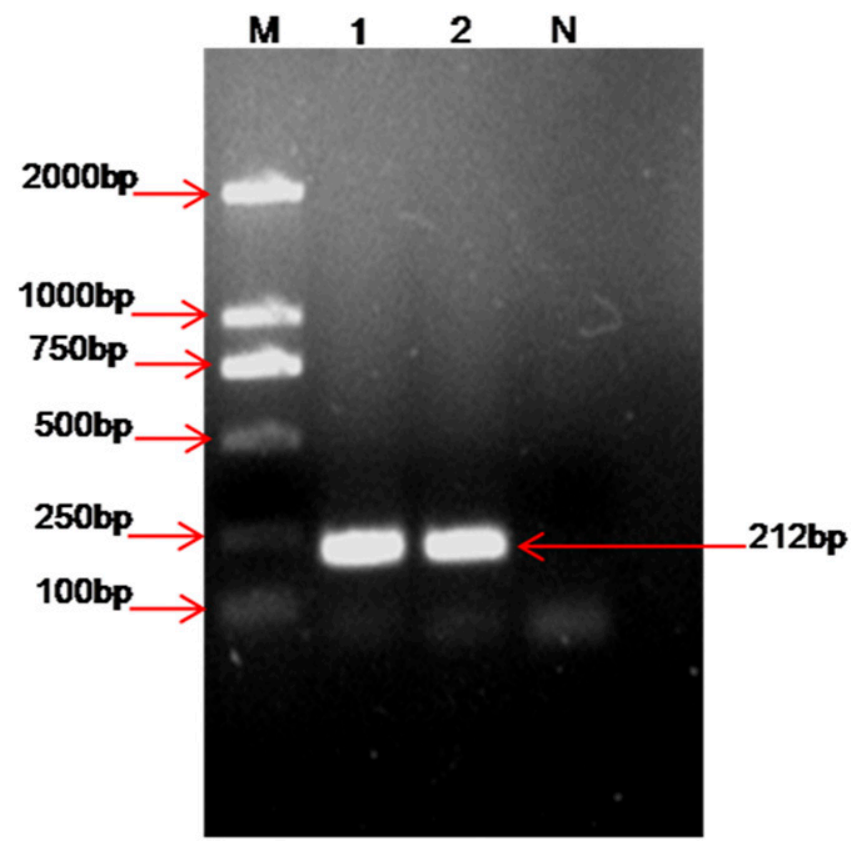

Fig. 2. Amplification of specific region in the UvG- $\beta 1$ gene of Ustilaginoidea virens using forward outer and backward outer primers. Lanes 1 and $2=U$. virens DNA, lane $\mathrm{N}=$ negative control (no DNA), and lane $\mathrm{M}=\mathrm{DL}$ 2,000-bp DNA size marker.

Table 2. Sequences of the primers used for amplification of the target sequence in gene $U v G-\beta 1$

\begin{tabular}{lll}
\hline Primer name & Primer type & \multicolumn{1}{c}{ Sequence 5' $\rightarrow \mathbf{3}^{\prime}$} \\
\hline F3 & Forward outer & GCTCCTGGGATTCTTTGGT \\
B3 & Backward outer & GCTCGATCGGGACAACCA \\
FIP (F1c-F2) & Forward inner & TTGTCGCGTTGCAAGGACACGGGCATTCGACTCGGAACAG \\
BIP (B1c-B2) & Backward inner & TTCACTGACATGTGCGCTGACCCGGTTTCGTGGAACGGATT \\
LoopF & Forward loop & CGATTACCGTGCGTGTTGGA \\
LoopB & Backward loop & TCCGCAGTTGAAAATATGG \\
\hline
\end{tabular}


program. Using forward and backward primers, the conventional PCR yielded high amounts of DNA on $1.0 \%$ agarose gel electrophoresis, with the fragment size of $212 \mathrm{bp}$ (Fig. 2). Colors of sky blue with HNB for LAMP and yellowish green with SYBR Green I were indicative of a positive reaction in comparison with the negative control (Fig. 3A and B). After the visual assessment, the reaction tubes were examined by gel electrophoresis, which showed a ladder-like pattern on the gel with the tubes with $U$. virens DNA only (Fig. 3C) The results confirmed that LAMP could be used for the detection and identification of rice false smut disease (Fig. 3).

Sensitivity of the LAMP and PCR assays. Sensitivity of the LAMP assay was examined using different concentrations of $U$. virens's genomic DNA. After ninefold serial dilution $\left(10\right.$ to $\left.10^{-8} \mu \mathrm{g} / \mu \mathrm{l}\right)$ of DNA, amplification was observed with all concentrations from 10

A

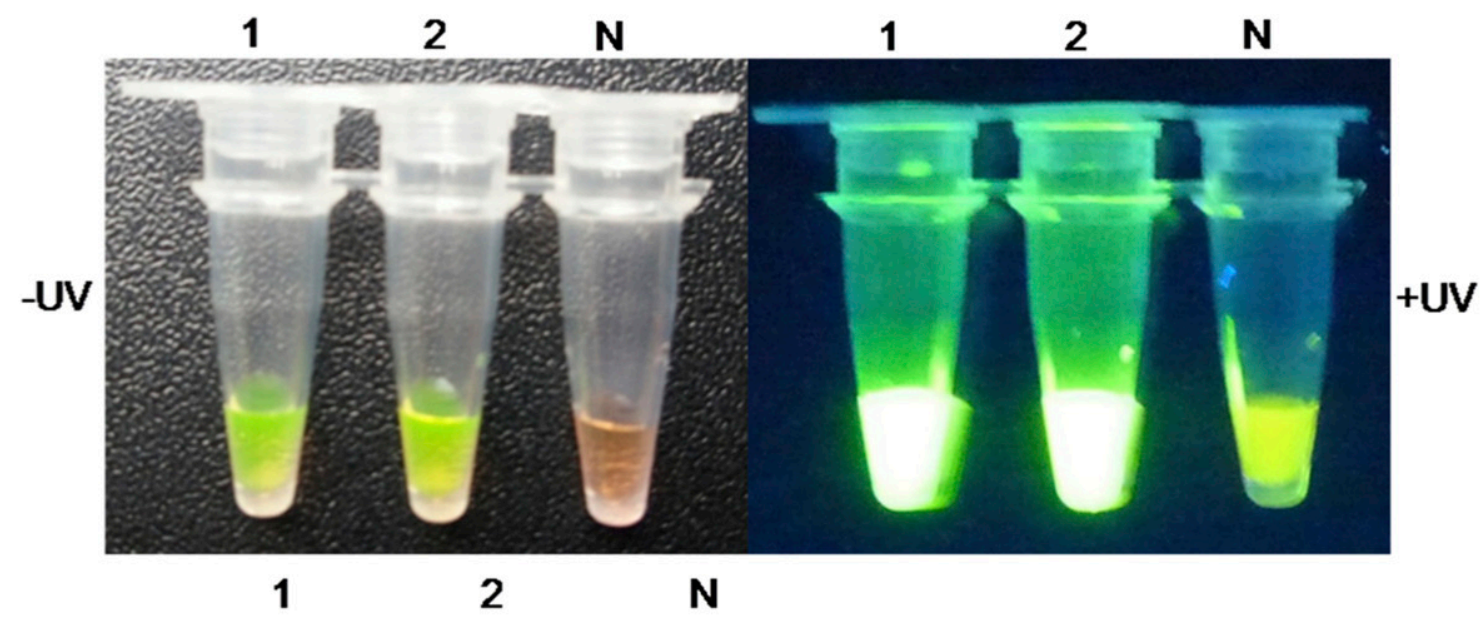

B
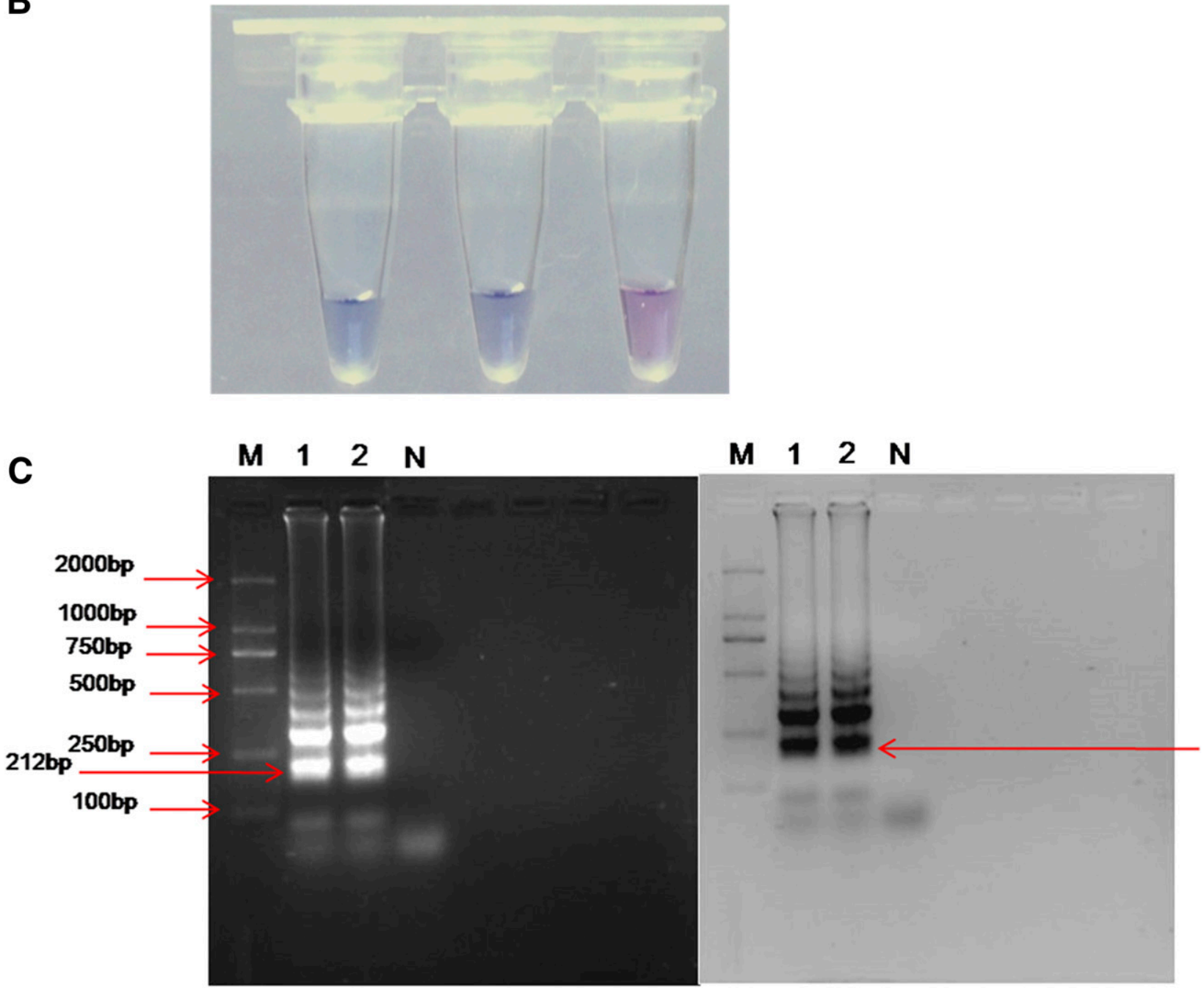

Fig. 3. Detection of Ustilaginoidea virens DNA using a loop-mediated isothermal amplification (LAMP) assay. A, Visualization by SYBR Green I in amplification tubes (tubes 1 and 2), The lighter shade indicates a positive reaction, which can be easily distinguished from the darker shade that indicates no reaction in the negative control under normal light (tube 3). The same positive sample, when visualized under UV transillumination, shows a shining fluorescence in tubes 1 and 2 (positive reaction). B, Visualization by hydroxynaphthol blue in amplification tubes indicating DNA amplification of $U$. virens (tubes 1 and 2); and $C, 2 \%$ agarose gel showing products from the LAMP reaction. Lanes 1 and 2 show a ladderlike pattern indicating positive reactions, lane $\mathrm{N}=$ negative control (no DNA), and lane $\mathrm{M}=\mathrm{DL}$ 2,000-bp DNA size marker. 


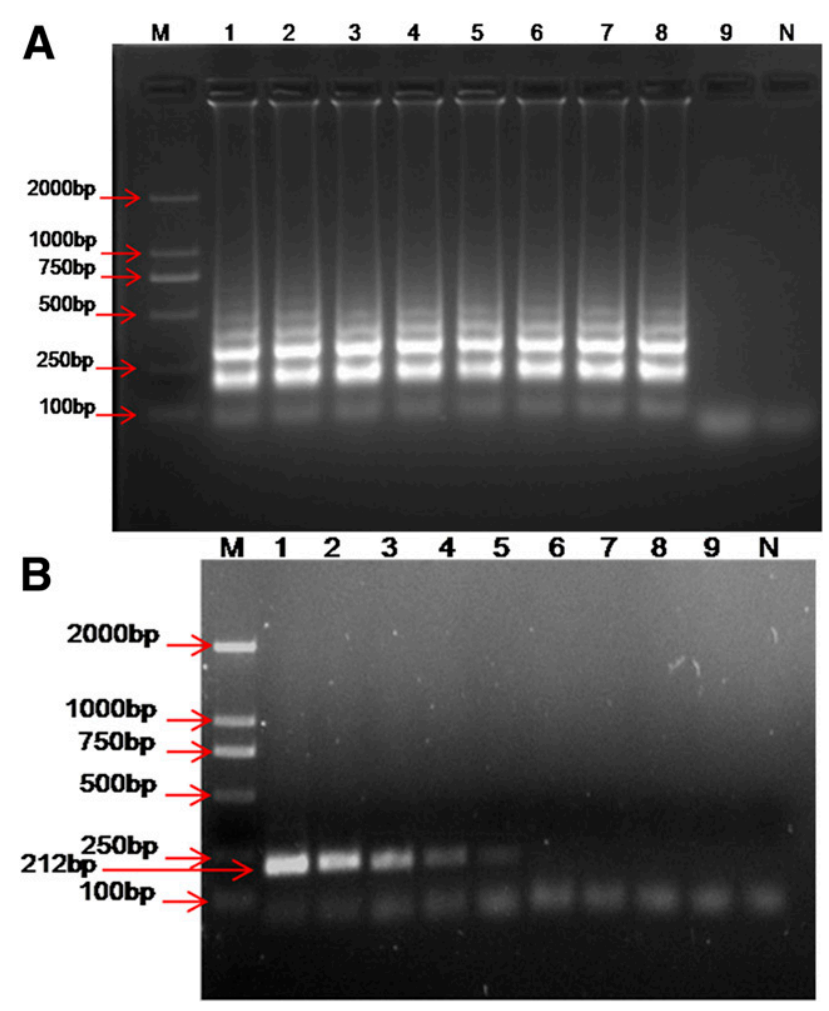

Fig. 4. Sensitivity of the loop-mediated isothermal amplification (LAMP) and polymerase chain reaction (PCR) test for the detection of Ustilaginoidea virens. A, LAMP assay and B, PCR assay. Lane M indicates DL 2,000-bp DNA size marker; lanes 1 to $9=$ template DNA concentrations $(10 \mu \mathrm{g}, 1 \mu \mathrm{g}, 100 \mathrm{ng}, 10 \mathrm{ng}, 1 \mathrm{ng}$, $100 \mathrm{pg}, 10 \mathrm{pg}, 1 \mathrm{pg}$, and $100 \mathrm{fg}$, respectively); and lane $\mathrm{N}$ = negative control (no DNA). to $10^{-7} \mu \mathrm{g} / \mu \mathrm{l}$, except the lower concentration, whereas the negative control showed no amplification under the same conditions (Fig. 4A). On the other hand, with conventional PCR, no DNA was amplified with concentrations less than $1 \mathrm{ng}$ (Fig. 4B). These results showed that the LAMP method was more efficient than PCR.

Specificity of the LAMP assay and detection of rice false smut pathogen in field samples and rice seed. Amplification of the DNA of $U$. virens but not of the 22 fungal pathogens confirmed the specificity of the primer sets for $U$. virens. After $1 \mathrm{~h}$ of reaction time at $65^{\circ} \mathrm{C}$, the color of SYBR Green I in the tubes containing $U$. virens's genomic DNA changed to yellowish green, compared with orange in the negative control (Fig. 5A and 5B), while fungal tubes and the negative control did not change color. This was indicative of the LAMP assay being capable of detecting and identifying $U$. virens. The same result was observed using PCR. Amplification reaction occurred in the tubes containing $U$. virens DNA as compared with no reaction in the negative control and other fungi (Fig. 5C and 5D). For direct analysis in the detection of $U$. virens in the field samples and rice seed, LAMP and PCR assays were used for the detection of $U$. virens in spikelets and seed. The results showed that the LAMP assay succeeded in detecting the infected rice spikelets (Fig. 6A) and seed (Fig. 6B) among healthy seed. Also, the same results were confirmed by PCR assay (Fig. 6C and $6 \mathrm{D})$. These results indicated that specific regions in the $U v G-\beta 1$ gene of $U$. virens (GU014921) could be used for the detection and identification of $U$. virens (Figs. 5 and 6) and the LAMP assay can be used for the detection of $U$. virens in the field samples and rice seed.

\section{Discussion}

The ability to survey and better manage plant diseases in the field requires effective, rapid, and reliable methods for detecting different pathogens. This technical demand has necessitated the development
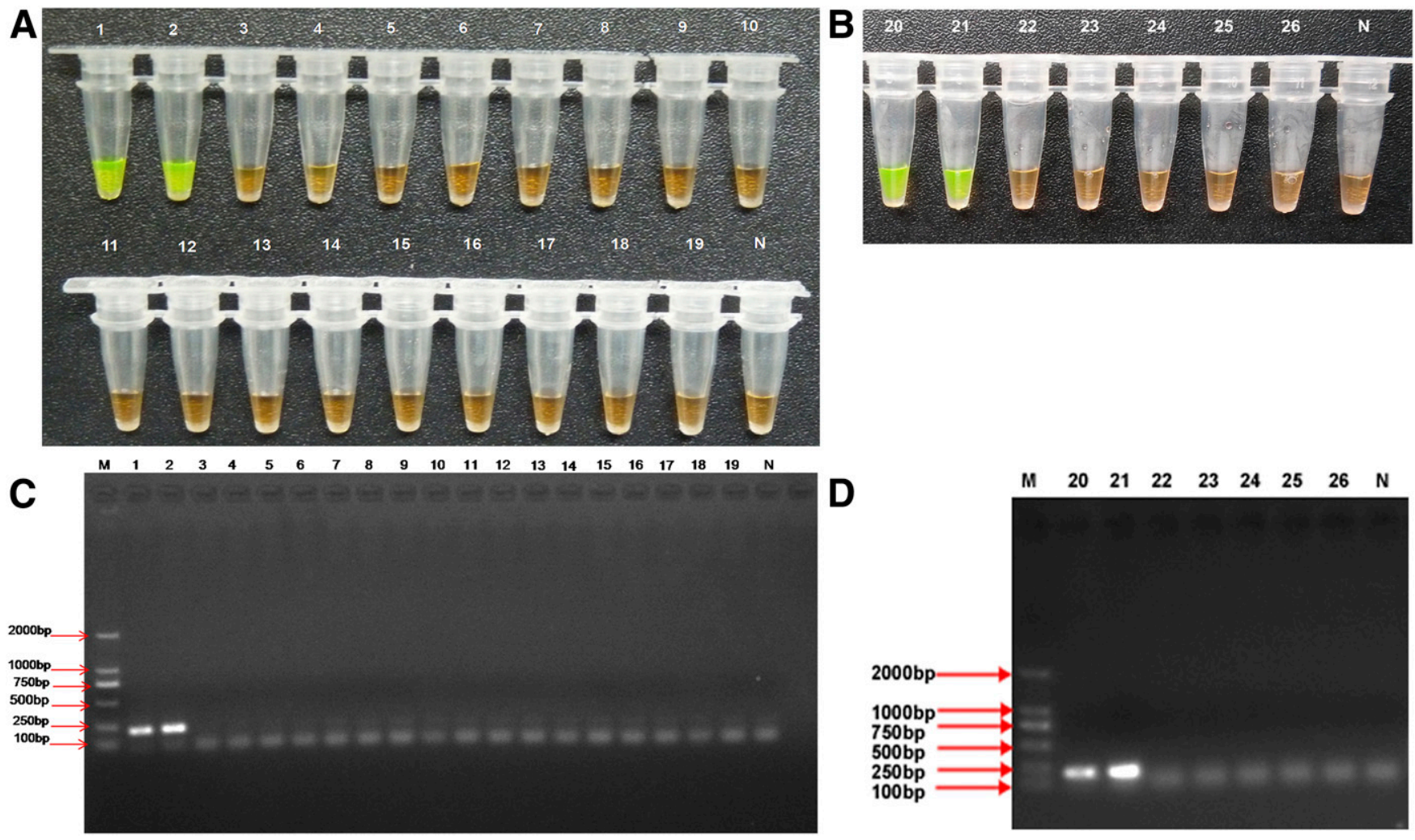

Fig. 5. Specific detection of gene UVG- $\beta 1$ using loop-mediated isothermal amplification (LAMP) and polymerase chain reaction (PCR). A and B, LAMP assay visualization by SYBR Green I in amplification tubes and C and D, PCR assay. Tubes and lanes 1 and $2=$ Ustilaginoidea virens; tubes and lanes 3 to $19=$ other tested fungi: Alternaria alternata, Ascochyta eriobotryae, Bipolaris sorokiniana, Botryosphaeria dothidea, Coniella granati, Coniothyrium diplodiella, Diplodia sp., Fusarium fujikuroi, F. oxysporum f. sp. melonis, Gaeumannomyces graminis, Glomerella acutata, Monilinia fructicola, Nigrospora sphaerica, Pestalotiopsis theae, Punicae granati, Pyricularia grisea, and Sclerotinia sclerotiorum, respectively); tubes and lanes 20 and 21 are $U$. virens; tubes and lanes 22 to $26=$ Metarhizium anisopliae, Claviceps purpurea, Rhizoctonia solani, Tilletia horrida, and F. graminearum, respectively. Lane $\mathrm{N}=$ negative control (no DNA) and lane $\mathrm{M}=\mathrm{DL}$ 2,000-bp DNA size marker. 

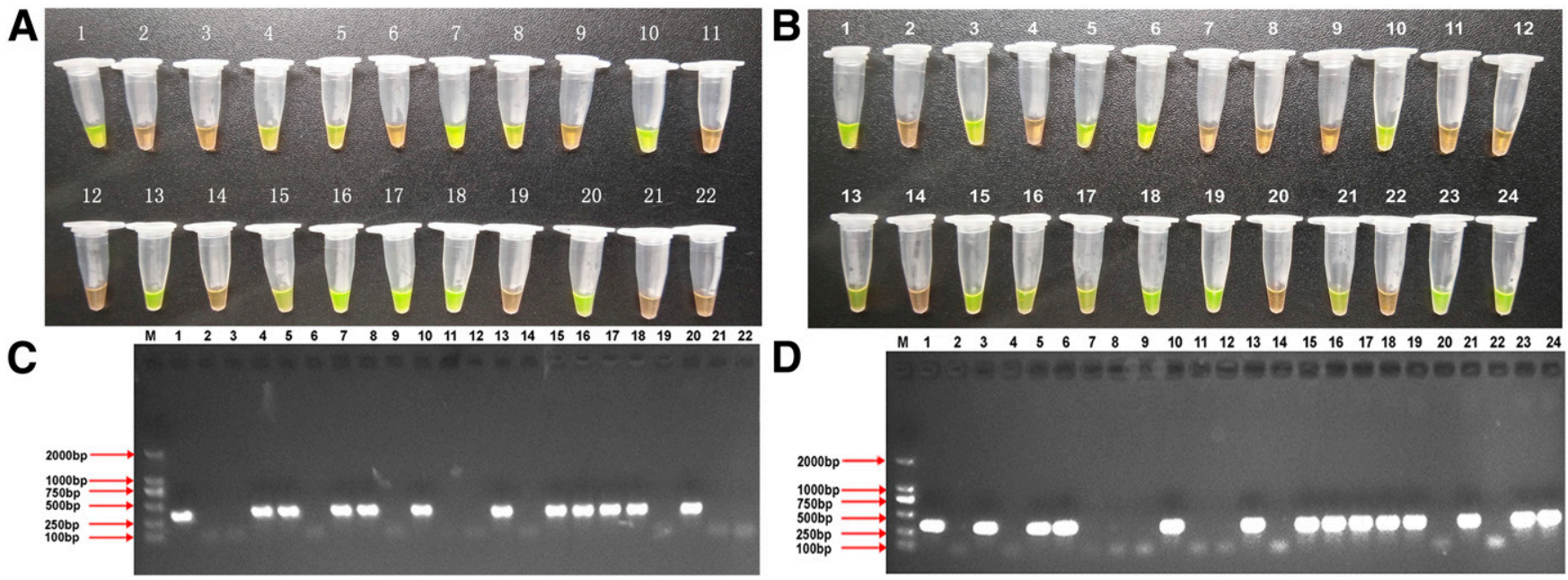

Fig. 6. Evaluation of the loop-mediated isothermal amplification (LAMP) and polymerase chain reaction (PCR) assays using rice seed samples. A, Using the LAMP assay for detection rice false smut disease in spikelets. Tube 1 is the positive control (genomic DNA [gDNA] of Ustilaginoidea virens), tube 2 is the negative control (no DNA), and tubes 3 to 22 are healthy and infected spikelets. B, Using the LAMP assay for detection rice false smut disease in rice seed. Tube 1 is the positive control (gDNA of $U$. virens), tube 2 is the negative control (no DNA), and tubes 3 to 24 are healthy seed and infected seed. The positive reaction (infected seed) shows a color change and all negative amplification reactions remain unchanged. C, Using the PCR assay for detection of rice false smut disease in spikelets. D, Using the PCR assay for detection of rice false smut disease in rice seed. Lane $1=$ the positive control (gDNA of $U$. virens) and lane $2=$ the negative control (no DNA). All negative reactions did not show any amplification. Lane M = DL 2,000-bp DNA size marker.

of new methods for the detection and identification of pathogens. The new methods must (i) be cheaper, to be easily used in the laboratory and field in developing countries; (ii) be equally used in the laboratory and field; (iii) be highly sensitive and specific; and (iv) avoid the use of sophisticated equipment. Most of the existing methods that detect and identify pathogens lack all or some of these requirements. They are costly and time consuming, and require post-PCR analysis such as gel electrophoresis and quantitative PCR software. LAMP is an alternative approach that addresses all of these issues and can be successfully used for the detection of plant-pathogenic bacteria, fungi, and viruses (Almasi et al. 2013; Dai et al. 2012; Denschlag et al. 2012; Tomlinson et al. 2007, 2010; Parida et al. 2005; Vaagt et al. 2013), as well as human and animal pathogens (Iwamoto et al. 2003; Li et al. 2014; Saetiew et al. 2011; Yang et al. 2014).

In this study, two pairs of primers (FIP-BIP and F3-B3) were used for targeting a specific region in gene $U v G-\beta 1$ for detection and identification of the rice false smut fungus. In addition, two loop primers (LF and LB) were used for enhancing efficiency of the reaction (Notomi et al. 2000; Zhao et al. 2015). The specific region in gene $U v G-\beta 1$ was 212 bp (Figs. 1 and 2), which after BLAST in the NCBI website showed no homology.

Many different factors affect the LAMP assay for successful amplification such as DNA quality, optimum amplification temperature, time to complete the amplification reaction (Zhao et al. 2015), and concentration of the $\mathrm{Mg}^{2+}$ ion (Goto et al. 2009). Previously, we have tested several reaction systems of the LAMP assay for the detection of $U$. virens and, finally, we found that the optimum temperature for successful amplification of DNA is $65^{\circ} \mathrm{C}$ for $60 \mathrm{~min}$. Presently, many different dyes are used for the detection and the successful amplification of DNA such as magnesium pyrophosphate-based, HNB, SYBR Green I, magnesium pyrophosphatem, ethidium bromide, and enefinder. In this study, the LAMP reaction tube was examined via HNB and SYBR Green I (Fig. 3A and B). Both dyes detected the difference between the positive and negative reactions, visible through naked eye. This is the simplest method that visually differentiates between positive and negative reactions and does not demand for any special equipment. It should be noted that opening the LAMP reaction tubes after the reaction is completed represents a high risk of contamination due to the high volume of LAMP product generated.

This study reports the detection sensitivity limit of LAMP primers. Amplification of about $1 \mathrm{pg}$ of $U$. virens target DNA in comparison with $1 \mathrm{ng}$ through conventional PCR proves the high sensitivity of LAMP primers. Previous studies have also reported LAMP to be more sensitive than conventional PCR for DNA amplification (Goto et al. 2009; Mori et al. 2004; Niessen and Vogel 2010; Yang et al. 2014; Zhao et al. 2015).

Also, we studied the specification of LAMP primers for detection of rice false smut fungus between different fungus species. The results showed that LAMP primers can detect $U$. virens among different species (Fig. 5). The assay specifically amplified only gene $U v G-\beta 1$; no cross-reactivity was seen with other fungi. This result was consistent with PCR and BLAST results in NCBI.

In conclusion, it can be inferred that the LAMP assay is useful for the rapid detection of $U$. virens in the field and laboratory. This study showed that the LAMP assay succeeded in detecting rice spikelets (Fig. 6A) and seed (Fig. 6B) infected by $U$. virens in the field. The LAMP technique excludes the need for sophisticated equipment such as a PCR machine or gel electrophoresis or gel-imaging systems for the detection of $U$. virens in the laboratory or field. This LAMP method is quite sensitive for detection of $U$. virens in rice spikelets at booting stage and seed, and could be a useful tool for pathologists in designing integrated control programs for rice false smut disease.

\section{Literature Cited}

Almasi, M. A., Ojaghkandi, M. A., Hemmatabadi, A., Hamidi, F., and Aghaei, S 2013. Development of colorimetric loop-mediated isothermal amplification assay for rapid detection of the tomato yellow leaf curl virus. J. Plant Pathol. Microbiol. 4:1-6.

Al-Soud, W. A., and Rådström, P. 2000. Effects of amplification facilitators on diagnostic PCR in the presence of blood, feces, and meat. J. Clin. Microbiol. 38:4463-4470.

Ashizawa, T., Takahashi, M., Arai, M., and Arie, T. 2012. Rice false smut pathogen, Ustilaginoidea virens, invades through small gap at the apex of a rice spikelet before heading. J. Gen. Plant Pathol. 78:255-259.

Ashizawa, T., Takahashi, M., Moriwaki, J., and Hirayae, K. 2010. Quantification of the rice false smut pathogen Ustilaginoidea virens from soil in Japan using real-time PCR. Eur. J. Plant Pathol. 128:221-232.

Atia, M. M. M. 2004. Rice false smut (Ustilaginoidea virens) in Egypt. J. Plant Dis Prot. 111:71-82.

Charoensopharat, K., Aukkanit, N., Thanonkeo, S., Saksirirat, W., Thanonkeo, P. and Akiyama, K. 2008. Targeted disruption of a $\mathrm{G}$ protein $\alpha$ subunit gene results in reduced growth and pathogenicity in Rhizoctonia solani. World J. Microbiol. Biotechnol. 24:345-351.

Chen, Y., Yao, J., Li, Y. F., Wang, W. X., Yang, X., and Zhang, A. F. 2014. Simple and rapid detection of rice false smut pathogen Ustilaginoidea virens in rice seeds. Phytoparasitica 42:371-375.

Dai, T. T., Lu, C. C., Lu, J., Dong, S., Ye, W., Wang, Y., and Zheng, X. 2012 Development of a loop-mediated isothermal amplification assay for detection of Phytophthora sojae. FEMS Microbiol. Lett. 334:27-34. 
Denschlag, C., Vogel, R. F., and Niessen, L. 2012. Hyd5 gene-based detection of the major gushing-inducing Fusarium spp. In a loop-mediated isothermal amplification (LAMP) assay. Int. J. Food Microbiol. 156:189-196.

Duan, Y., Ge, C., Zhang, X., Wang, J., and Zhou, M. G. 2014a. A rapid detection method for the plant pathogen Sclerotinia sclerotiorum based on loop-mediated isothermal amplification (LAMP). Australas. Plant Pathol. 43:61-66.

Duan, Y., Zhang, X., Ge, C., Wang, Y., Cao, J., Jia, X., Wang, J., and Zhou, M. 2014b. Development and application of loop-mediated isothermal amplification for detection of the F167Y mutation of carbendazim-resistant isolates in Fusarium graminearum. Sci. Rep. 4: Article 7094.

Fan, J., Guo, X. Y., Huang, F., Li, Y., Liu, Y. F., Li, L., Xu, Y. J., Zhao, J. Q., Xiong, H., Yu, J. J., and Wang, W. 2014. Epiphytic colonization of Ustilaginoidea virens on biotic and abiotic surfaces implies the widespread presence of primary inoculum for rice false smut disease. Plant Pathol. 63: 937-945.

Fan, J., Yang, J., Wang, Y. Q., Li, G. B., Li, Y., Huang, F., and Wang, W. M. 2016. Current understanding on Villosicalava virens, a unique flower-infecting fungus causing rice false smut disease. Mol. Plant Pathol. 17:1321-1330.

FAO. 2015. FAOSTAT, FAO Statistical Databases. Online publication. Food and Agriculture Organization (FAO) of the United Nations, Rome. http://www.fao. org/faostat/en/\#home

Goto, M., Honda, E., Ogura, A., Nomoto, A., and Hanaki, K. 2009. Colorimetric detection of Loop-mediated isothermal amplification reaction by using hydroxynaphthol blue. Biotechniques 46:167-172.

Hsueh, Y. P., Xue, C., and Heitman, J. 2007. G protein signaling governing cell fate decisions involves opposing $\mathrm{G} \alpha$ subunits in Cryptococcus neoformans. Mol. Biol. Cell 18:3237-3249.

Hu, M., Luo, L., Wang, S., Liu, Y., and Li, J. 2014. Infection processes of Ustilaginoidea virens during artificial inoculation of rice panicles. Eur. J. Plant Pathol. 139:67-77.

Iwamoto, T., Sonobe, T., and Hayashi, K. 2003. Loop-mediated isothermal amplification for direct detection of Mycobacterium tuberculosis complex, $M$. avium, and $M$. intracellulare in sputum samples. J. Clin. Microbiol. 41: 2616-2622.

Koiso, Y., Li, Y., Iwasaki, S., Hanaoka, K., Kobayashi, T., Sonoda, R., Fujita, Y., Yaegashi, H., and Sato, Z. 1994. Ustiloxin, anti-mitotic cyclic peptides from false smut balls on rice panicles caused by Ustilaginoidea virens. J. Antibiot. 47:765-773.

Laborte, A. G., Bie, K. D., Smaling, E. M. A., Moya, P. F., Boling, A. A., and Ittersum, M. K. V. 2012. Rice yields and yield gaps in Southeast Asia: Past trends and future outlook. Eur. J. Agron. 36:9-20.

Li, C., Chen, J., Shi, H., Zhang, X., Shi, D., Han, X., Chi, Y., and Feng, L. 2014. Rapid detection of porcine kobuvirus in feces by reverse transcription loopmediated isothermal amplification. Virol. J. 11:73.

Li, Y., Koiso, Y., Kobayashi, H., Hashimoto, Y., and Iwasaki, S. 1995. Ustiloxins, new antimitotic cyclic peptides: Interaction with porcine brain tubulin. Biochem. Pharmacol. 49:1367-1372.

Liu, L., Wang, L., Huang, W., Liu, E., and Huang, S. 2010. Cloning, expression and sequence analysis of $G$ protein $\beta$ subunit gene of rice false smut pathogen Ustilaginoidea virens. Chin. J. Rice Sci. 24:353-359.

Ludueña, R. F., Roach, M. C., Prasad, V., Banerjee, M., Koiso, Y., Li, Y., and Iwasaki, S. 1994. Interaction of ustiloxin A with bovine brain tubulin. Biochem. Pharmacol. 47:1593-1599.

Monteiro, L., Bonnemaison, D., Vekris, A., Petry, K. G., Bonnet, J., Vidal, R., Cabrita, J., and Mégraud, F. 1997. Complex polysaccharides as PCR inhibitors in feces: Helicobacter pylori model. J. Clin. Microbiol. 35:995-998.

Mori, Y., Kitao, M., Tomita, N., and Notomi, T. 2004. Real-time turbidimetry of LAMP reaction for quantifying template DNA. J. Biochem. Biophys. Methods 59:145-157.

Niessen, L., and Vogel, R. F. 2010. Detection of Fusarium graminearum DNA using a loop-mediated isothermal amplification (LAMP) assay. Int. J. Food Microbiol. 140:183-191.

Nishimura, M., Park, G., and Xu, J. R. 2003. The G-beta subunit MGB1 is involved in regulating multiple steps of infection-related morphogenesis in Magnaporthe grisea. Mol. Microbiol. 50:231-243.

Niu, J. H., Jian, H., Guo, Q. X., Chen, C. L., Wang, X. Y., Liu, Q., and Guo, Y. D. 2012. Evaluation of loop-mediated isothermal amplification (LAMP) assays based on 5S rDNA-IGS2 regions for detecting Meloidogyne enterolobii. Plant Pathol. 61:809-819.

Notomi, T., Okayama, H., Masubuchi, H., Yonekawa, T., Watanabe, K., Amino, N., and Hase, T. 2000. Loop-mediated isothermal amplification of DNA. Nucleic Acids Res. 28:e63.

Ono, K., and Uehara, K. 1949. Damages of rice by false smut disease. Agric. Hortic. 24:489-490.

Parida, M., Horioke, K., Ishida, H., Dash, P. K., Saxena, P., Jana, A. M., Islam, M. A., Inoue, S., Hosaka, N., and Morita, K. 2005. Rapid detection and differentiation of dengue virus serotypes by a real-time reverse transcriptionloop-mediated isothermal amplification assay. J. Clin. Microbiol. 43:28952903.

Saetiew, C., Limpaiboon, T., Jearanaikoon, P., Daduang, S., Pientong, C., Kerdsin, A., and Daduang, J. 2011. Rapid detection of the most common high-risk human papilloma viruses by loop-mediated isothermal amplification. J. Virol. Methods 178:22-30.

Song, J. H., Wei, W., Lv, B., Lin, Y., Yin, W. X., Peng, Y. L., Schnabel, G., Huang, J. B., Jiang, D. H., and Luo, C. X. 2016. Rice false smut fungus hijacks the rice nutrients supply by blocking and mimicking the fertilization of rice ovary. Environ. Microbiol. 18:3840-3849.

Tanaka, E., Kumagawa, T., Ito, N., Nakanishi, A., Ohta, Y., Suzuki, E., Adachi, N., Hamada, A., Ashizawa, T., Ohara, T., and Tsuda, M. 2017. Colonization of the vegetative stage of rice plants by the false smut fungus Villosiclava virens, as revealed by a combination of species-specific detection methods. Plant Pathol. 66:56-66.

Tang, Y. X., Jin, J., Hu, D. W., Yong, M. L., Xu, Y., and He, L. P. 2013 Elucidation of the infection process of Ustilaginoidea virens (teleomorph: Villosiclava virens) in rice spikelets. Plant Pathol. 62:1-8.

Tilman, D., Cassman, K. G., Matson, P. A., Naylor, R., and Polasky, S. 2002 Agricultural sustainability and intensive production practices. Nature 418: 671-677.

Tomlinson, J. A., Barker, I., and Boonham, N. 2007. Faster, simpler, more-specific methods for improved molecular detection of Phytophthora ramorum in the field. Appl. Environ. Microbiol. 73:4040-4047.

Tomlinson, J. A., Dickinson, M. J., and Boonham, N. 2010. Detection of Botrytis cinerea by loop-mediated isothermal amplification. Lett. Appl. Microbiol. 51: 650-657.

Tzima, A. K., Paplomatas, E. J., Tsitsigiannis, D. I., and Kang, S. 2012. The G protein $\beta$ subunit controls virulence and multiple growth and developmentrelated traits in Verticillium dahliae. Fungal Genet. Biol. 49:271-283.

Vaagt, F., Haase, I., and Fischer, M. 2013. Loop-mediated isothermal amplification (LAMP)-based method for rapid mushroom species identification. J. Agric Food Chem. 61:1833-1840.

Wang, P., Perfect, J. R., and Heitman, J. 2000. The G-protein $\beta$ subunit GPB1 is required for mating and haploid fruiting in Cryptococcus neoformans. Mol. Cell. Biol. 20:352-362.

Yang, B. Y., Liu, X. L., Wei, Y. M., Wang, J. Q., He, X. Q., Jin, Y., and Wang, Z. J. 2014. Rapid and sensitive detection of human astrovirus in water samples by loop-mediated isothermal amplification with hydroxynaphthol blue dye. BMC Microbiol. 14:38

Young, A. 1999. Is there really spare land? A critique of estimates of available cultivable land in developing countries. Environ. Dev. Sustain. 1:3-18.

Yu, H. Y., Seo, J. A., Kim, J. E., Han, K. H., Shim, W. B., Yun, S. H., and Lee, Y. W. 2008. Functional analyses of heterotrimeric $\mathrm{G}$ protein $\mathrm{G} \alpha$ and $\mathrm{G} \beta$ subunits in Gibberella zeae. Microbiology 154:392-401.

Zhang Y., Zhang K., Fang A., Han Y., Yang J., Xue M., Bao J., Hu D., Zhou B. Sun X., Li S., Wen M., Yao N., Ma L.-J., Liu Y., Zhang M., Huang F., Luo C., Zhou L., Li J., Chen Z., Miao J., Wang S., Lai J., Xu J.-R., Hsiang T., Peng Y.-L. and Sun W.. 2014. Specific adaptation of Ustilaginoidea virens in occupying host florets revealed by comparative and functional genomics. Nat. Commun. 5: Article 3849

Zhao, W., Wang, T., and Qi, R. 2015. Ypt1 gene-based detection of Phytophthora sojae in a loop-mediated isothermal amplification assay. J. Plant Dis. Prot. 122: 66-73.

Zhou, Y. L., Izumitsu, K., Sonoda, R., Nakazaki, T., Tanaka, E., Tsuda, M., and Tanaka, C. 2003. PCR-based specific detection of Ustilaginoidea virens and Ephelis japonica. J. Phytopathol. 151:513-518. 